\title{
Baseline well-being, perceptions of critical incidents, and openness to debriefing in community hospital emergency department clinical staff before COVID-19, a cross-sectional study
}

\author{
Laura Cantu* (i) and Listy Thomas
}

\begin{abstract}
Background: Emergency department personnel routinely bear witness to traumatic experiences and critical incidents that can affect their own well-being. Peer support through debriefing has demonstrated positive impacts on clinicians' well-being following critical incidents. This study explored community hospital emergency department staff's perceptions of critical incidents, assessed openness to debriefing and measured baseline wellbeing. Our analysis provides a baseline of provider well-being immediately prior to the local onset of COVID-19. The potential need for additional resources to support frontline providers during the pandemic can be evaluated.

Method: We conducted a cross-sectional study for 4-weeks prior to the first COVID-19 case in Connecticut using a survey offered to an interprofessional group of emergency department clinical staff. The main outcome measures were the Hospital Anxiety and Depression Scale (HADS) and the Professional Quality of Life (ProQOL) scale. Pearson's chi-square test was used to identify significant differences in perceptions of critical incidents and debriefings between professional categories. One-way ANOVA and Tukey's test were used to analyze significant differences in well-being between professional categories.

Results: Thirty-nine clinical personnel from St. Vincent's Emergency Department responded to the survey. Events frequently selected as critical incidents were caring for critically ill children (89.7\%), mass casualty events (84.6\%), and death of a patient (69.2\%). Critical incidents were commonly reported (81.6\%) as occurring once per week. Additionally, $76.2 \%$ of participants reported wanting to discuss a critical incident with their team. Across all respondents, $45.7 \%$ scored borderline or abnormal for anxiety, 55.9\% scored moderate for burnout, and 55.8\% scored moderate to high for secondary traumatic stress.

* Correspondence: lacantu@qu.edu

Frank H. Netter MD School of Medicine, 370 Bassett Rd, North Haven, CT 06473, USA

(c) The Author(s). 2020 Open Access This article is licensed under a Creative Commons Attribution 4.0 International License, which permits use, sharing, adaptation, distribution and reproduction in any medium or format, as long as you give appropriate credit to the original author(s) and the source, provide a link to the Creative Commons licence, and indicate if changes were made. The images or other third party material in this article are included in the article's Creative Commons licence, unless indicated otherwise in a credit line to the material. If material is not included in the article's Creative Commons licence and your intended use is not permitted by statutory regulation or exceeds the permitted use, you will need to obtain permission directly from the copyright holder. To view a copy of this licence, visit http://creativecommons.org/licenses/by/4.0/. The Creative Commons Public Domain Dedication waiver (http://creativecommons.org/publicdomain/zero/1.0/) applies to the data made available in this article, unless otherwise stated in a credit line to the data. 


\begin{abstract}
(Continued from previous page)
Conclusions: At baseline, providers reported caring for critically ill children, mass casualty events, and death of a patient as critical incidents, which typically occurred once per week. Death of a patient occurs at increased frequency during the protracted mass casualty experience of COVID-19 and threatens provider well-being. Receptiveness to post-event debriefing is high but the method is still underutilized. With nearly half of staff scoring borderline or abnormal for anxiety, burnout, and secondary traumatic stress at baseline, peer support measures should be implemented to protect frontline providers' well-being during and after the pandemic.
\end{abstract}

Keywords: Debriefing, Peer support, Well-being, HADS, ProQOL, Critical incident, COVID-19, Secondary traumatic stress, Burnout

\section{Background}

Emergency department clinical staff manage traumatic events as a routine part of their careers in medicine. Although these staff members have not experienced the patient's trauma first-hand, the strong emotional reactions providers may feel following caring for patients who have experienced such events can affect them in many ways; including cognitively, behaviorally, emotionally, and physically [1-4]. As a result, frontline healthcare workers are at risk for secondary traumatic stress responses that range from exhaustion and avoidance to hypervigilance, physical illness, and presenteeism $[5,6]$. At baseline, healthcare workers report high levels of burnout, secondary traumatic stress, and suicidal ideation, which are correlated to decreases in performance and patient care $[2,7-11]$. The new demands placed on providers by COVID-19 will likely negatively impact providers' mental health $[12,13]$. An earnest assessment of the utilization of stress mitigation strategies must be conducted for the protection of frontline providers.

Discussion-based stress interventions in real time (in situ) have been developed to improve peer support wellbeing and providers' ability to return to work, while reducing stress manifestations $[14,15]$. Critical incident stress debriefing (CISD), an older and more structured form of debriefing, has come under scrutiny for possibly worsening PTSD symptoms or secondary traumatic stress. Notably, the literature that suggests these adverse outcomes included studies which used CISD outside the model's intended framework, such that debriefing occurred one-on-one with patients instead of in a group setting with frontline providers $[16,17]$. Newer methods of post-event debriefing, such as the INFO and DISC ERN models, $[18,19]$ are structured to avoid many of the perceived pitfalls of CISD through their more immediate timing and provider-implemented style [20]. In this paper, the term "debriefing" will be used to indicate a form of peer support, discussion-based stress intervention.

These low resource methods have demonstrated efficacy for interprofessional staff following pre-selected clinical events or critical incidents [21-24]. A critical incident has been defined by Magyar et al as, "a selfdefined traumatic event that causes individuals to experience such strong emotional responses that usual coping mechanisms are ineffective" [25]. Pediatric and adult resuscitations are common pre-selected clinical events which should initiate a debriefing [14, 19, 24, 26]. Clinical events previously recognized as distressing for staff or cited as critical incidents in the literature include death of a patient, multi-trauma, and death of young patients $[1,19,27]$. To cope with emotionally challenging patient cases, nurses have previously reported reliance upon peer support and physicians have voiced a preference for a more formal support structure [22, 23, 26].

The aim of this study is to describe the well-being of community hospital emergency department clinical staff immediately prior to the local onset of COVID-19 and identify their perceptions surrounding critical incidents and post-event, discussion-based interventions. The current low level of hospital instituted peer support programs and current risks to health professionals' wellbeing needs to be addressed [28]. By demonstrating healthcare workers' openness to peer support, this study serves as an evidence-based call to action for the implementation of in situ debriefing to mitigate stress impacts during the pandemic.

\section{Methods \\ Study design}

This cross-sectional study was conducted in the 4-weeks immediately prior to the announcement of the first COVID-19 positive case in a Connecticut state resident [29]. The study site was a community hospital emergency department with no formal peer support debriefing program, akin to most community hospitals [27, 30]. Survey distribution began in February 2020 and responses were collected through early March 2020. The study used self-report questionnaires in Qualtrics, a secure HIPAA compliant HITRUST certified survey software published by Qualtrics, to collect demographic data from the interprofessional group of respondents. The survey questions collected staff's experiences and perspectives surrounding critical incidents and post-event 
discussion-based interventions. Levels of anxiety, depression, burnout, compassion satisfaction, and secondary traumatic stress were measured using validated clinical questionnaires and scoring scales, described below in more detail. All survey responses were collected anonymously.

\section{Study participants}

The online survey was distributed through a department-wide e-mail to all emergency department clinical staff at a community hospital in Connecticut. Study participants encompassed the following clinical roles: registered nurses (RN), physician assistants (PA), physicians, resident physicians, and emergency department technicians (ED Tech).

\section{Demographic data}

Demographic data collected from the participants included gender, clinical role, and years of practice.

\section{Critical incidents}

Participants were given the following definition for a critical incident prior to responding to questions regarding their experiences and perspectives, "A critical incident is a self-defined traumatic event that causes individuals to experience such strong emotional responses that usual coping mechanisms are ineffective."

\section{Hospital anxiety and depression scale (HADS)}

The HADS was used to measure the levels of anxiety and depression in the medical staff [31-33]. The HADS questionnaire contained 14 items, seven items relevant to each anxiety and depression, graded for experience within the past 7 days. Each item was scored between 0 and 3 and the scores within each category were totaled for a cumulative score ranging $0-21$. Higher scores indicate more abnormal levels of anxiety and depression.

\section{Professional quality of life (ProQOL)}

The ProQOL version 5 assessment was used to measure the levels of compassion satisfaction, burnout, and secondary traumatic stress in the medical staff $[34,35]$. The ProQOL is a five-point Likert scale consisting of 30 items. Scores cumulate within each of the three outcome measures for a total score ranging from 10-50. Higher scores indicate higher levels of compassion satisfaction, burnout, and secondary traumatic stress.

The ProQOL defines measures in the following ways, "Compassion satisfaction is about the pleasure you derive from being able to do your work well" [36]. Secondary traumatic stress is the development of emotional duress due to indirect exposure to trauma derived while helping others [37].

\section{Statistical analysis}

For categorical variables, including demographic data and self-report data regarding critical incidents, proportions were reported. Pearson's chi-square test was used to further analyze for associations between professional categories and responses to critical incident and debriefing questions. Due to the small sample size, the registered nurse and physician assistant professional categories were collapsed into a single group. Outcomes of the HADS and ProQOL scales were reported as proportions and one-way ANOVA was employed to assess for differences between mean well-being scores and demographic groups. Further analysis of statistically significant findings was conducted with Tukey's post hoc test. All $P$-values were two-sided and, if below 0.05 , the results were considered statistically significant. Analyses were conducted using IBM SPSS Statistics for Windows Version 26 (IBM Corp., Armonk, N.Y., USA).

\section{Results}

Participants

In total, 46 people consented to the survey. For this study, seven respondents who did not respond to all questions or returned the survey after the first positive COVID-19 local case were excluded, leaving a sample of 39. This sample represents $32.5 \%$ of the emergency department's 120 employees.

A total of 39 staff members (6 physicians, 27 combined registered nurses and physician assistants, and 6 emergency department technicians) completed the demographics and opinion portion of the survey, 35 staff members (5 physicians, 24 registered nurses and physician assistants, and 6 emergency department technicians) completed the HADS, and 34 staff members (4 physicians, 24 registered nurses and physician assistants, and 6 emergency department technicians) completed the ProQOL. The demographic data of the participants are shown in Table 1.

\section{Critical incidents}

The clinical event most commonly selected as a critical incident was "caring for a critically ill child" by $89.74 \%$ $(n=35)$ of respondents. Frequency of clinical events considered critical incidents are shown in Fig. 1. The "Other" category consisted of 2 respondents who wrote in "death of a child."

The proportion of respondents who selected each clinical event are shown by professional category in Table 2 . Pearson's chi-square analysis was used to identify the associations between clinical role or years of practice and clinical events considered critical incidents. There was a statistically significant association between selection of mass casualty event as a critical incident and clinical role $(\mathrm{X}(1)=6.850, p=.033)$, with $50 \%$ selection amongst 
Table 1 Demographic data represented in the sample

\begin{tabular}{lll}
\hline Variable & Number & Percent \\
\hline Gender & 29 & $74.4 \%$ \\
Female & 10 & $25.6 \%$ \\
Male & & \\
Clinical Role & 6 & $15.4 \%$ \\
Physician & 27 & $69.2 \%$ \\
RN/PA & 6 & $15.4 \%$ \\
ED Tech & & \\
Years of Practice & 4 & $10.3 \%$ \\
$<3$ years & 16 & $41.0 \%$ \\
3-10 years & 7 & $17.9 \%$ \\
11-20 years & 12 & $30.8 \%$ \\
20+ years &
\end{tabular}

emergency department technicians compared to $83.3 \%$ of physicians and $92.6 \%$ of registered nurses and physician assistants. There was no statistically significant association between any clinical events and years of practice.

The proportion of participants who reported participating in a critical incident during the last 12 months was $97.4 \%(n=38)$ and the most common frequency for critical incidents was reported as "once per week" by $81.6 \%(n=31)$ of respondents (Table 3$)$.

\section{Openness to debriefings}

The proportion of respondents who reported having discussed a critical incident with their team during the past 12 months was $64.1 \%(n=25)$ and $100 \%(n=25)$ of those respondents reported finding it useful to their wellbeing. Of all respondents, $79.5 \%(n=31)$ reported wanting to discuss a critical incident with their team in the past 12 months. There was a statistically significant association between desire to discuss a critical incident and years of practice $(\chi(1)=9.229, p=.026)$, with the highestproportion from the $<3$ years of practice $(100 \%$, $n=4)$ and $11-20$ years of practice $(100 \%, n=7)$ groups and the lowest proportion amongst the 3-10 years of practice group $(56.3 \%, n=9)$ as shown in Fig. 2. There was no statistically significant association between wanting to discuss a critical incident and clinical role $(\mathrm{X}(1)=$ $0.725, p=.696)$.

\section{Baseline well-being}

The levels of anxiety and depression as measured by the HADS and levels of compassion satisfaction, burnout, and secondary traumatic stress as measured by the ProQOL have been reported in Table 4.

There was a statistically significant difference between clinical roles for mean secondary traumatic stress scores as determined by one-way ANOVA $(\mathrm{F}(2,31)=5.811$, $p=.007)$. A Tukey post-hoc test revealed that secondary traumatic stress was statistically significantly lower in the combined RN/PA group $(21.46 \pm 6.043)$ compared to ED Techs $(30.83 \pm 6.369, p=.011)$. There was no statistically significant difference between the physicians and ED Techs $(p=.115)$ or registered nurses and physician assistants $(p=.987)$. There was no statistically significant difference between the gender or years of practice groups for mean secondary traumatic stress scores or between any groups for the remaining HADS and ProQOL measures.

\section{Discussion}

\section{Critical incidents}

Prior to the local onset of COVID-19 in Connecticut, the majority of frontline providers in this study identified caring for critically ill children (89.7\%), mass casualty events $(84.6 \%)$, and death of a patient $(69.2 \%)$ as

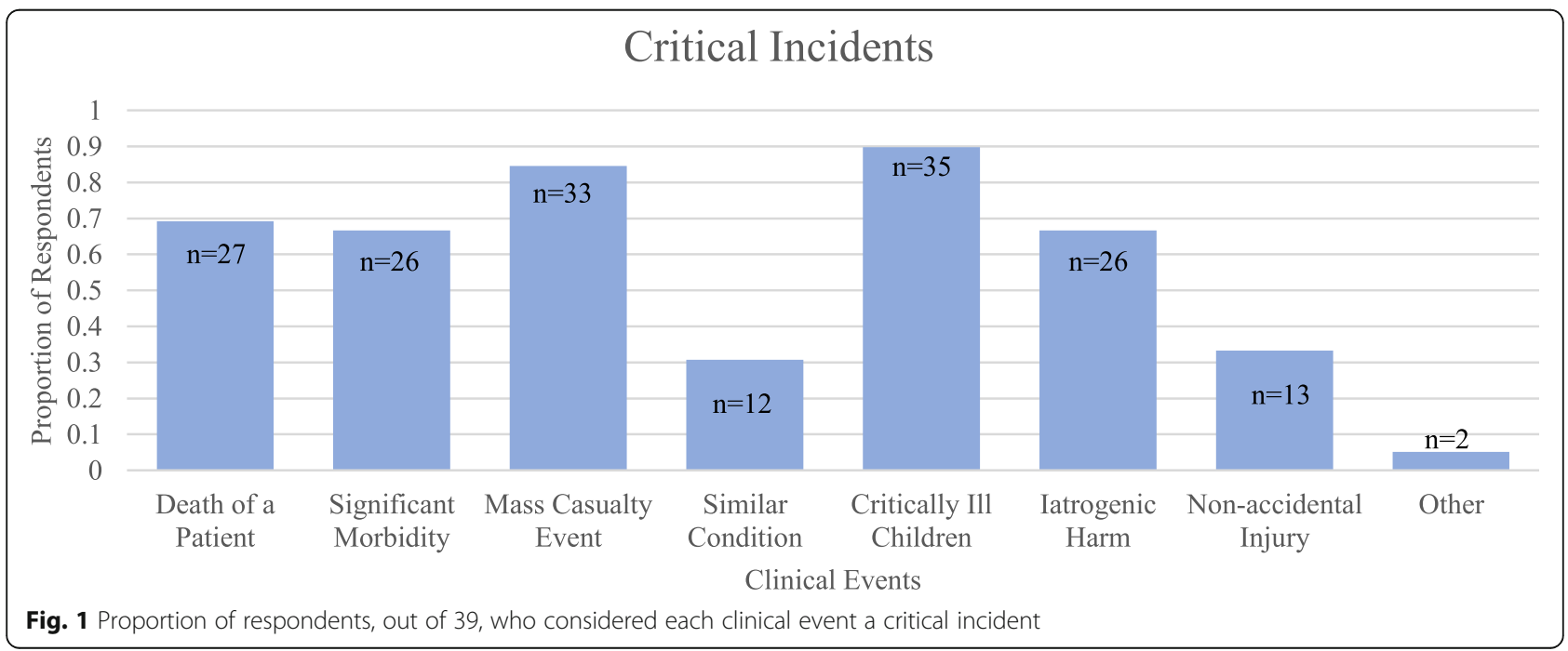


Table 2 Clinical events selected as critical incidents by professional category

\begin{tabular}{|c|c|c|c|c|c|c|c|}
\hline $\begin{array}{l}\text { Professional } \\
\text { category }\end{array}$ & $\begin{array}{l}\text { Death of a } \\
\text { patient }\end{array}$ & $\begin{array}{l}\text { Injury resulting in } \\
\text { significant morbidity }\end{array}$ & $\begin{array}{l}\text { Mass casualty } \\
\text { event }\end{array}$ & $\begin{array}{l}\text { Patient with same } \\
\text { condition as provider }\end{array}$ & $\begin{array}{l}\text { Critically } \\
\text { ill child }\end{array}$ & $\begin{array}{l}\text { latrogenic } \\
\text { harm }\end{array}$ & $\begin{array}{l}\text { Non-accidental } \\
\text { injury }\end{array}$ \\
\hline \multicolumn{8}{|l|}{ Clinical Role } \\
\hline Physician & $66.7 \%(n=4)$ & $83.3 \%(n=5)$ & $83.3 \%(n=5)$ & $33.3 \%(n=2)$ & $100 \%(n=6)$ & $66.7 \%(n=4)$ & $50 \%(n=3)$ \\
\hline $\mathrm{RN} / \mathrm{PA}$ & $70.4 \%(n=19)$ & $63 \%(n=17)$ & $92.6 \%(n=25)$ & $25.9 \%(n=7)$ & $\begin{array}{l}85.2 \%(n= \\
23)\end{array}$ & $\begin{array}{l}70.4 \%(n= \\
19)\end{array}$ & $25.9 \%(n=7)$ \\
\hline ED Tech & $66.7 \%(n=4)$ & $66.7 \%(n=4)$ & $50 \%(n=3)$ & $50 \%(n=3)$ & $100 \%(n=6)$ & $50 \%(n=3)$ & $50 \%(n=3)$ \\
\hline \multicolumn{8}{|c|}{ Practice Years } \\
\hline$<3$ years & $75 \%(n=3)$ & $75 \%(n=3)$ & $75 \%(n=3)$ & $50 \%(n=2)$ & $100 \%(n=4)$ & $50 \%(n=2)$ & $50 \%(n=2)$ \\
\hline $3-10$ years & $62.5 \%(n=10)$ & $62.5 \%(n=10)$ & $75 \%(n=12)$ & $25 \%(n=4)$ & $\begin{array}{l}81.3 \%(n= \\
13)\end{array}$ & $\begin{array}{l}68.8 \%(n= \\
11)\end{array}$ & $18.8 \%(n=3)$ \\
\hline $\begin{array}{l}11-20 \\
\text { years }\end{array}$ & $85.7 \%(n=6)$ & $71.4 \%(n=5)$ & $85.7 \%(n=6)$ & $28.6 \%(n=2)$ & $100 \%(n=7)$ & $71.4 \%(n=5)$ & $42.9 \%(n=3)$ \\
\hline $20+$ years & $66.7 \%(n=8)$ & $66.7 \%(n=8)$ & $100 \%(n=12)$ & $33.3 \%(n=4)$ & $\begin{array}{l}91.7 \%(n= \\
11)\end{array}$ & $66.7 \%(n=8)$ & $41.7 \%(n=5)$ \\
\hline
\end{tabular}

critical incidents that would render usual coping mechanisms ineffective. These findings are consistent with a descriptive, cross-sectional study conducted in 13 pediatric emergency departments across Australia and New Zealand, which found $81 \%$ of senior nurses and physicians believed death of a patient was a critical incident warranting debriefing [27]. At baseline, critical incidents were predominantly reported at a frequency of only once per week by $81.6 \%$ of providers. Perceptions of what clinical events are critical incidents may also be impacted in the post-COVID-19 landscape. Specifically, "caring for a patient with a condition that you or a loved one has," which had the lowest respondent selection $(30.8 \%)$, may increase in prevalence due to the potential development of fear amongst healthcare providers regarding contracting or transmitting COVID-19 to family members.

\section{Openness to debriefings}

The majority of participants indicated a desire to discuss a critical incident with their team in the past 12 months, demonstrating a receptiveness to in situ stress interventions like post-event discussions or debriefings. There was a statistically significant difference between the proportion of providers who wanted to discuss a critical incident across years of practice; with the 3-10 years of practice group reporting the lowest proportion (56.3\%), compared to $100 \%$ of providers with $<3$ and $11-20$ years

Table 3 Reported frequency of experiencing a critical incident within the last 12 months

\begin{tabular}{lll}
\hline Frequency of $\mathbf{C l}$ & Number & Percent \\
\hline Once per week & 31 & $81.6 \%$ \\
Multiple times per week & 5 & $13.2 \%$ \\
Multiple times per shift & 2 & $5.3 \%$ \\
\hline
\end{tabular}

of practice or $91.7 \%$ of providers with $20+$ years of practice. The lower rate among mid-career providers may be attributed to self-perceptions of resilience. These outcomes reveal an opportunity for specific programming aimed at normalizing and promoting peer support among providers with 3-10 years of practice. Given the high rate of receptiveness across providers with more years of practice, this may also create a channel for senior mentorship to improve receptiveness across junior mentees.

There was no difference in openness to post-event discussion across clinical roles, further indicating potential for high uptake by interprofessional teams. Previous studies conducted in pediatric emergency department nurse populations have reported similar preferences for peer based support following critical incidents [22]. Given the potential use of travel nurses and outside medical providers to supplement hospital staffing, easily self-implemented, low-resource debriefings may provide foundation for building peer support amongst less familiar teams.

\section{Baseline well-being}

Roughly half of all medical workers surveyed experienced borderline or abnormal anxiety (45.7\%), moderate burnout (55.9\%), or moderate to high secondary traumatic stress (55.8\%). This level of burnout is consistent with previously reported levels of physician burnout. A call to action by the Massachusetts Medical Society in 2019 already considered the state of physician well-being a public health crisis [9]. Healthcare workers, who may face disillusionment as a result of this pandemic, would benefit from wider accessibility to various forms of stress interventions [38].

To our knowledge, this study is the first to report baseline well-being, opinions of critical incidents, and 


\section{Openness to Debriefing}

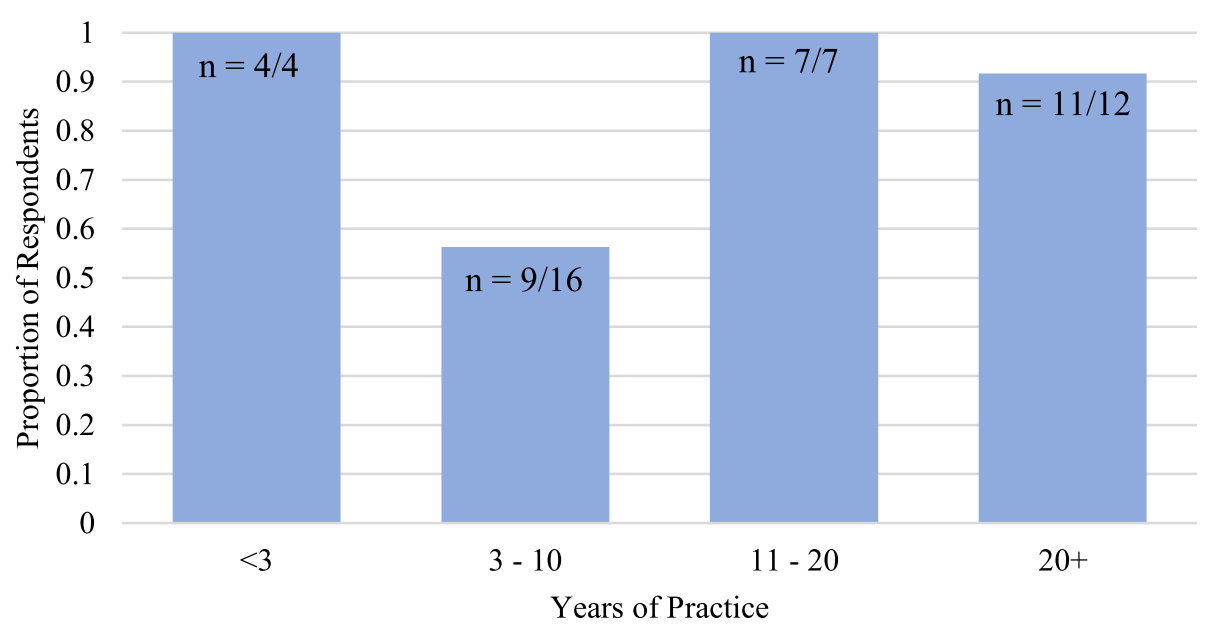

Fig. 2 Proportion of respondents, by years of practice, who reported wanting to discuss a critical incident with their team

openness to debriefing amongst emergency department clinical staff immediately prior to the local onset of COVID-19. Several limitations of the study should be noted. The age of respondents was not collected in demographic data, although it would have been interesting to correlate the age of respondents with their markers of well-being. The small sample size collected at a single site reduces the power to detect group differences and the ability to generalize from the findings. Additionally, nonresponse bias may have influenced our findings. Providers who completed surveys may have had stronger feelings regarding mental health support compared to providers who declined, resulting in an unrepresentative sample. Baseline well-being may differ for emergency departments with institutionalized peer support programs.

At present, a longitudinal study aims to capture weekly impacts from critical incidents within this same population in order to assess how evolving COVID-19 cases manifest as critical incidents and effect provider wellbeing through time. Future plans include reassessment of HADS, ProQOL, and perceptions of critical incidents and debriefings after COVID-19 cases decrease to directly assess the impact of the pandemic on providers. Hospitals should also aim to collect local data on provider well-being, implement post-event stress debriefings, and assess stress mitigation interventions for efficacy.

\section{Conclusion}

Our cross-sectional study of community hospital emergency department clinical staff in one institution found providers considered mass casualty events and death of a patient to be critical incidents. At baseline, providers experienced levels of anxiety, burnout, and secondary traumatic stress at levels previously identified as detrimental to personal and public health. All respondents who had discussed a critical incident with their team found this experience useful to their wellbeing. The majority of providers, including those with no prior debriefing experience, reported a desire for post-event, teambased discussions. The absence of institution supported debriefings and peer support groups in community hospitals is an area for improvement and discussion-based stress reduction interventions could be included in

Table 4 Overall results of the HADS and ProQOL scales

\begin{tabular}{llllll}
\hline HADS & Normal & Borderline abnormal & Abnormal & Mean & Std. Deviation \\
Anxiety & $54.3 \%(n=19)$ & $25.7 \%(n=9)$ & $20.0 \%(n=7)$ & 7.20 & 3.954 \\
Depression & $85.7 \%(n=30)$ & $11.4 \%(n=4)$ & $2.9 \%(n=1)$ & 3.37 & 3.040 \\
ProQOL & Low & Moderate & High & Mean & Std. Deviation \\
Compassion satisfaction & $0 \%(n=0)$ & $64.7 \%(n=22)$ & $35.3 \%(n=12)$ & 39.44 & 6.165 \\
Burnout & $44.1 \%(n=15)$ & $55.9 \%(n=19)$ & $0 \%(n=0)$ & 23.47 & 6.278 \\
Secondary traumatic stress & $44.1 \%(n=15)$ & $52.9 \%(n=18)$ & $2.9 \%(n=1)$ & 23.24 & 6.867 \\
\hline
\end{tabular}


COVID-19 response trainings to promote peer support and frontline provider well-being.

This study was conducted prior to the onset of the pandemic, and in light of the likelihood of increased negative mental health impacts from COVID-19, this data may indicate a particularly vulnerable position for providers. Acute and potentially enduring moral injury sustained from the potential shortages of appropriate proper protective equipment (PPE), lack of evidence based data to inform decision making, crisis standards of care, and the trauma of witnessing large numbers of individuals experiencing serious illness and death in the absence of family may all contribute to high levels of stress among frontline healthcare providers during and after the pandemic. These experiences are compounded by the stress of social isolation and lack of appropriate human interactions that would otherwise mitigate stress. Researchers will likely find significant impairments in anxiety, burnout, and secondary traumatic stress as the lingering effects of COVID-19 effect frontline workers. Peer support measures that facilitate debriefings should be implemented to protect frontline providers' wellbeing during and after the pandemic.

\section{Supplementary information}

Supplementary information accompanies this paper at https://doi.org/10. 1186/s12873-020-00372-5.

Additional file 1. Table: Survey questions

\section{Abbreviations}

HADS: Hospital anxiety and depression scale; ProQOL: Professional quality of life; ED Tech: Emergency department technician; RN: Registered nurse; PA: Physician assistant; COVID-19: Coronavirus virus disease 2019

\section{Acknowledgements}

Richard S. Feinn, PhD provided statistical guidance and analysis support. Linda Durhan, MD provided technical writing guidance.

\section{Authors' information (optional)}

$\mathrm{LT}$ is an emergency medicine physician at St. Vincent's Medical Center and associate professor of medical sciences at Frank H. Netter MD School of Medicine.

LC is a third-year medical student who has given a TEDx Talk on physician well-being in addition to self-publishing a debriefing tutorial video for coping with COVID-19 on shift (YouTube: Quick Tip for Healthcare Providers Defusing on Shift) [39].

\section{Authors' contributions}

LC analyzed and interpreted the survey data and was the major contributo in writing the manuscript. LT guided protocol design and directed data collection. All authors read and approved the final manuscript.

\section{Funding}

Capstone Project Funding provided by Frank H. Netter MD School of Medicine, Scholarly Reflection \& Capstone/Concentration Course. The funder, Frank H. Netter MD School of Medicine, provided a set amount of capstone funding for all medical students. They did not participate in project development or data collection in any way.

\section{Availability of data and materials}

The datasets used and/or analyzed during the current study are available from the corresponding author on reasonable request.

\section{Ethics approval and consent to participate}

Ethical considerations for this study in regard to the use of human subjects were approved by the St. Vincent's Medical Center IRB. We obtained written consent from all participants.

\section{Consent for publication}

Not applicable.

\section{Competing interests}

LC and LT are currently researching the efficacy of debriefing methods for interprofessional use in acute care settings.

The authors have no other competing interests to declare.

Received: 8 June 2020 Accepted: 28 September 2020

Published online: 15 October 2020

\section{References}

1. Blacklock E. Interventions following a critical incident: developing a critical incident stress management team - ScienceDirect. Arch Psychiatr Nurs. 2012;26:2-8

2. Glasberg AL, Eriksson S, Norberg A. Burnout and 'stress of conscience' among healthcare personnel. J Adv Nurs. 2007:57(4):392-403.

3. Rotenstein LS, Ramos MA, Torre M, Segal JB, Peluso MJ, Guille C, et al. Prevalence of depression, depressive symptoms, and suicidal ideation among medical students: a systematic review and meta-analysis. JAMA. 2016;316(21):2214-36.

4. Maloney C. Critical incident stress debriefing and pediatric nurses: an approach to support the work environment and mitigate negative consequences. Pediatr Nurs. 2012;38(2):110-3.

5. Penix EA, Kim PY, Wilk JE, Adler AB. Secondary traumatic stress in deployed healthcare staff. Psychol Trauma 2019;11(1):1-9.

6. Guitar NA, Molinaro ML. Vicarious trauma and secondary traumatic stress in health care professionals. UWOMJ. 2017:86(2):42-3.

7. Tawfik DS, Profit J, Morgenthaler TI, Satele DV, Sinsky CA, Dyrbye LN, et al. Physician burnout, well-being, and work unit safety grades in relationship to reported medical errors. Mayo Clin Proc. 2018;93(11):1571-80.

8. Fred HL, Scheid MS. Physician burnout: causes, consequences, and (?) cures. Tex Heart Inst J. 2018;45(4):198-202.

9. Jha AK, lliff AR, Chaoui AA, Defossez S, Bombaugh MC, Miller YR. A crisis in health care: a call to action on physician burnout. 2019.

10. Shanafelt TD, Noseworthy $\mathrm{JH}$. Executive leadership and physician wellbeing: nine organizational strategies to promote engagement and reduce burnout. Mayo Clin Proc. 2017;92(1):129-46.

11. Gazoni FM, Durieux ME, Wells L. Life after death: the aftermath of perioperative catastrophes. Anesth Analg. 2008;107(2):591-600.

12. Lu W, Wang H, Lin Y, Li L. Psychological status of medical workforce during the COVID-19 pandemic: a cross-sectional study. Psychiatry Res. 2020;288: 112936.

13. Xiao H, Zhang Y, Kong D, Li S, Yang N. The effects of social support on sleep quality of medical staff treating patients with coronavirus disease 2019 (COVID-19) in January and February 2020 in China. Med Sci Monit. 2020;26:923549.

14. Copeland D, Liska H. Implementation of a post-code pause: extending postevent debriefing to include silence. J Trauma Nurs. 2016;23(2):58-64.

15. Harder N, Lemoine J, Harwood R. Psychological outcomes of debriefing healthcare providers who experience expected and unexpected patient death in clinical or simulation experiences: a scoping review. J Clin Nurs. 2020;29(3-4):330-46.

16. Rose SC, Bisson J, Churchill R, Wessely S. Psychological debriefing for preventing post traumatic stress disorder (PTSD). Cochrane Database Syst Rev. 2002;2:1-49.

17. van Emmerik AA, Kamphuis JH, Hulsbosch AM, PMG E. Single session debriefing after psychological trauma: a meta-analysis. Lancet. 2002; 360(9335):766-71.

18. Rose S. Charge nurse facilitated clinical debriefing in the emergency department | Canadian Journal of Emergency Medicine | Cambridge Core. 2018; Available at: https://www.cambridge.org/core/journals/canadian- 
journal-of-emergency-medicine/article/charge-nurse-facilitated-clinicaldebriefing-in-the-emergency-department/CC224433937ACBA849491A66 EBC9593D. Accessed 04/15/, 2020.

19. Mullan PC, Wuestner E, Kerr TD, Christopher DP, Patel B. Implementation of an in situ qualitative debriefing tool for resuscitations. Resuscitation. 2013; 84(7):946-51.

20. Kessler D. Debriefing in the emergency department after clinical events: a practical guide. Ann Emerg Med. 2014;65(6):690-8.

21. O'Connor J, Jeavons S. Perceived effectiveness of critical incident stress debriefing by Australian nurses. Aust J Adv Nurs. 2003;20(4):22-9.

22. Clark PR, Polivka B, Zwart M, Sanders R. Pediatric emergency department staff preferences for a critical incident stress debriefing. J Emerg Nurs. 2019; 45(4):403-10.

23. Zheng R, Lee SF, Bloomer MJ. How nurses cope with patient death: a systematic review and qualitative meta-synthesis. J Clin Nurs. 2018;27(1-2): e39-49.

24. Cheng A, Hunt EA, Donoghue A, Nelson-McMillan K, Nishisaki A, LeFlore J, et al. Examining pediatric resuscitation education using simulation and scripted debriefing: a multicenter randomized trial. JAMA Pediatr. 2013; 167(6):528-36.

25. Magyar. Review article: debriefing critical incidents in the emergency department. Emerg Med Australas 2010;22:499-506.

26. Gillen J, Koncicki ML, Hough RF, Palumbo K, Choudhury T, Daube A, et al. The impact of a fellow-driven debriefing program after pediatric cardiac arrests. BMC Med Educ. 2019;19(1):272.

27. Theophilos T, Magyar J, Babl FE. Debriefing critical incidents in the paediatric emergency department: current practice and perceived needs in Australia and New Zealand. Emerg Med Australas. 2009;21(6):479-83.

28. Gougoulis A, Trawber R, Hird K, Sweetman G. 'Take 10 to talk about it': Use of a scripted, post-event debriefing tool in a neonatal intensive care unit. Paediatr Child Health. 2020;56(7):1134-9. https://doi.org/10.1111/jpc.14856. Epub 2020 Mar 20. PMID: 32196132.

29. The Office of Governor Ned Lamont. Governor Lamont Announces First Positive Case of Novel Coronavirus Involving a Connecticut Resident [press release] (03/08/2020) [cited 2020 April 2]. Available from: https://portal.ct. gov/Office-of-the-Governor/News/Press-Releases/2020/03-2020/GovernorLamont-Announces-First-Positive-Case-of-Novel-Coronavirus-Involving-aConnecticut-Resident.

30. Ireland S, Gilchrist J, Maconochie I. Debriefing after failed paediatric resuscitation: a survey of current UK practice. Emerg Med J. 2008;25(6): 328-30.

31. Snaith RP. The hospital anxiety and depression scale. Health Qual Life Outcomes. 2003;1:29.

32. Julian LJ. Measures of anxiety. Arthritis Care Res 2011:63(0):1-11.

33. Bjelland I, Dahl AA, Haug T, Neckelmann D. The validity of the hospital anxiety and depression scale: an updated literature review. J Psychosom Res. 2002;52(2):69-77.

34. Hemsworth D, Baregheh A, Aoun S, Kazanjian A. A critical enquiry into the psychometric properties of the professional quality of life scale (ProQol-5) instrument. Appl Nurs Res. 2018:39:81-8.

35. Beaumont E, Durkin M, Martin CJH, Carson J. Measuring relationships between self-compassion, compassion fatigue, burnout and well-being in student counsellors and student cognitive behavioural psychotherapists: a quantitative survey. Couns Psychother Res. 2016;16(1):15-23.

36. The Center for Victims of Torture. Professional Quality of Life Measure. Available at: https://www.proqol.org/ProQol_Test.htmlfiles/534/ProQol_Test. html. Accessed 15 Apr 2020

37. Figley CR. Compassion fatigue: Toward a new understanding of the costs of caring. In: Secondary traumatic stress: Self-care issues for clinicians, researchers, and educators. Baltimore, MD, US: The Sidran Press; 1995. p. 3-28.

38. Myers D, David F. Disasters in Mental Health Services A Primer for Practitioners Psychosocial. DHHS 2005; publication no. ADM 90-358.

39. Laura Cantu. Quick Tip for Healthcare Providers - Defusing on Shift. 2020 April 10,https://youtu.be/9XOaBP9073M.

\section{Publisher's Note}

Springer Nature remains neutral with regard to jurisdictional claims in published maps and institutional affiliations.

\section{Ready to submit your research? Choose BMC and benefit from:}

- fast, convenient online submission

- thorough peer review by experienced researchers in your field

- rapid publication on acceptance

- support for research data, including large and complex data types

- gold Open Access which fosters wider collaboration and increased citations

- maximum visibility for your research: over $100 \mathrm{M}$ website views per year

At $\mathrm{BMC}$, research is always in progress.

Learn more biomedcentral.com/submissions 